\title{
Es muss sich rechnen
}

Ziel jeder geschäftlichen Tätigkeit ist es, Gewinne zu erwirtschaften. Aufgabe des Managements ist es, dies möglichst erfolgreich zu tun. Um Unternehmen entsprechend steuern zu können, werden vielfältige Verfahren zum Einsatz gebracht, die eine qualifizierte Einschätzung ermöglichen sollen, ob und wann sich eine Investition - etwa in neue Maschinen finanziell auszahlen wird. Auch die Frage „Selbst machen oder einkaufen?" kann so oft beantwortet werden.

Wichtig ist, dass nicht nur die reinen Kosten dabei im Blick behalten werden, sondern auch die Qualität. Etwas selbst zu machen, mag billiger sein, aber zum Beispiel zu lange dauern.

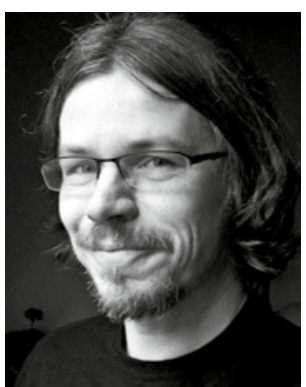

Peter Pagel Chefredakteur

Wenn es auf dem Markt Firmen gibt, die eine Qualität anbieten, die jahrelange Erfahrungen voraussetzt, ist einkaufen meist besser.

Kosten-Nutzen-Rechnungen werden in allen Bereichen eines Unternehmens aufgemacht, vom Materialeinkauf, über die Kosten für Arbeitsmittel bis hin zu Investitionen in die IT-Sicherheit. Muss es immer die beste Lösung sein und vor allem an jeder Stelle? Oder reicht auch eine gute, aber kostengünstigere Variante? Der effektive Einsatz der finanziellen Mittel erfordert immer, genau hinzuschauen. Wie hoch wäre zum Beispiel der maximale Schaden, den ein Durchbrechen der Sicherheitsvorkehrungen in einem Bereich hervorrufen könnte? Wer sich um solche Fragen nicht kümmert, läuft Gefahr, da viel zu investieren, wo es gar nicht nötig ist, aber dafür an anderen Stellen, wo es wichtig wäre, am falschen Ende zu sparen. „Sparen“ kommt dann gelegentlich ziemlich teuer.

Das Schwerpunktthema in diesem Heft (ab Seite 8) betreuten Prof. Dr. Andrea Back und Prof. Dr. Peter Mertens aus unserem Advisory Board zusammen mit der Redaktion.

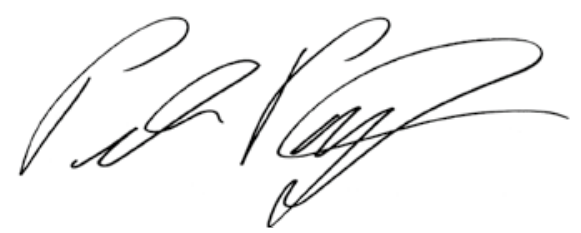

Peter Pagel 